\title{
PENYULUHAN JAJANAN, MAKANAN DAN KANTIN SEHAT DI SEKOLAH SMA 2 BATANG ANAI KECAMATAN BATANG ANAI KABUPATEN PADANG PARIAMAN
}

\author{
I Ketut Budaraga ${ }^{1}$, Ramaiyulis $^{2}$,Ellyza Nurdin ${ }^{3}$, Rosnita Rauf $^{4}$
}

\begin{abstract}
Abstrak
Jajanan, makanan dan kantin sehat sehat merupakan kebutuhan anak-anak sekolah yang punya andil besar dalam menumbuhkan generasi berprestasi kedepan. Permasalahan sekarang ini sering ketersediaan jajanan, makanan dan kantin sehat kurang tersedia khususnya di sekolah SMA 2 Batang Anai sehingga perlu dilakukan penyuluhan. Tujuan kegiatan penyuluhan ini memberikan informasi masalah jajanan,makanan dan kantin sehat kepada anak-anak sekolah, pengelola kantin masyarakat sekitar sekolah yang berjualan di sekolah. Metode yang digunakan menggunakan metode ceramah dan tanya jawab (diskusi). Kegiatan diadakan aula SMA 2 Batang Anai pada tanggal 7 Januari 2019 diikuti oleh 30 peserta. Hasil penyuluhan menunjukkan peserta sangat antosias mengikuti kegiatan ini sampai selesai. Harapan peserta agar kegiatan ini berlanjut secara terus menerus setiap awal tahun.
\end{abstract}

Kata kunci : Penyuluhan, jajanan, makanan, sehat, sekolah

\begin{abstract}
Healthy snacks, food and healthy canteen are the needs of school children who have a big contribution in growing the next generation of achievers. The current problem is often the availability of snacks, healthy food and canteens is less available, especially in the SMA 2 Batang Anai school so counseling is needed. The purpose of this counseling activity is to provide information on snacks, food and healthy canteen problems to school children, canteen managers of the community around the school who sell at school. The method used uses the lecture method and question and answer (discussion). The activity was held at the Batang Anai 2 High School hall on January 7, 2019 and was attended by 30 participants. The results of the counseling showed that the participants were very enthusiastic about joining this activity until it was finished. The participants hope that this activity will continue continuously at the beginning of each year.
\end{abstract}

Keywords: Extension, snacks, food, health, school

\footnotetext{
${ }^{1}$ Staf pengajar Fakultas Pertanian Universitas Ekasakti ketut_budaraga@yahoo.com, budaraga1968@gmail.com

${ }^{2}$ Staf Pengajar Politani Payakumbuh

${ }^{3}$ Staf pengajar Fakultas Peternakan Universitas Andalas

${ }^{4}$ Staf pengajar Fakultas Teknik Universitas Ekasakti
} 


\section{Pendahuluan}

Makanan yang sehat merupakan bagian yang esensial bagi proses pertumbuhan dan perkembangan anak, serta sebagai dasar pemeliharaan kesehatan, baik bagi anak maupun orang dewasa. Sejalan dengan perkembangan zaman, semakin banyak bahan kimia yang dikembangkan dan digunakan sebagai bahan tambahan dalam jajanan dan makanan. Tujuan penggunaan zat-zat tersebut antara lain sebagai taste enhancer, food coloring, dan preservatives (Satriyasa B.K., et.al., 2017).

Berdasarkan penelitian BBPOM RI pada tahun 2007, didapatkan bahwa sekitar 45\% jajanan anak sekolah yang sampelnya diambil dari 26 BBPOM di Indonesia tidak memenuhi syarat untuk dikonsumsi. Bahan kimia berbahaya yang sering disalahgunakan sebagai zat aditif pada jajanan dan makanan antara lain boraks/asam borat, tawas, formalin dan rhodamin B, sehingga membuat pangan yang sehat menjadi tidak sehat (BBPOM RI, 2009).

Makanan memiliki arti penting dalam kehidupan manusia. Selain menyediakan zat-zat yang diperlukan untuk sumber tenaga dan pertumbuhan, makanan juga menyediakan zat-zat yang diperlukan untuk mendukung kehidupan tubuh yang sehat. Karena itu untuk meningkatkan kehidupan manusia diperlukan adanya persediaan makanan yang memadai baik dari segi kualitas maupun kuantitas. Dari segi kualitas, selain mengandung semua zat yang diperlukan oleh tubuh makanan juga harus memenuhi syarat keamanan.

Makanan yang aman merupakan faktor yang penting untuk meningkatkan derajat kesehatan. Dalam Undang-undang RI No. 7 Tahun 1996 tentang pangan, keamanan pangan didefinisikan sebagai kondisi dan upaya yang diperlukan untuk mencegah pangan dari kemungkinan cemaran biologis, kimia, benda-benda lain yang dapat mengganggu, merugikan dan membahayakan kesehatan manusia.

Penyakit yang ditimbulkan karena pangan yang tercemar telah menjadi masalah di dunia. Berdasarkan analisis data yang berhasil dihimpun saat ini, kasuskasus penyakit bawaan makanan (foodborne disease) atau keracunan makanan masih cukup tinggi. Kasus keracunan makanan di Indonesia terus meningkat dari tahun ke tahun. Kondisi saat ini di Indonesia, khususnya pada anak-anak, masih mengalami masalah gizi ganda (double burden), yaitu kekurangan gizi dan kelebihan gizi. Berdasarkan data Riset Kesehatan Dasar (Riskesdas) 2010 prevalensi status gizi (Indikator IMT/U) anak usia 6-12 tahun dengan kategori sangat kurus 4,6\%, kurus $7,6 \%$, normal 78,6\% dan gemuk 9,2\%. Prevalensi status gizi (indikator TB/U) anak dengan kategori stunting (sangat pendek 15,1\%, pendek 20\%) dan normal 64,5\%. Prevalensi anemia, berdasarkan data Depkes (2008)bahwa prevalensi anemia pada anak usia sekolah sebesar 47,2\%. (Anonim, 2013).

Masalah keamanan pangan perlu ditangani secara bersama baik oleh pemerintah, produsen, maupun konsumen. Produsen pangan bertanggung jawab untuk mengendalikan keamanan pangan yang dihasilkan, konsumen bertanggung jawab untuk memantau keamanan pangan yang ada di sekitarnya, sedangkan pemerintah bertanggung jawab untuk mengatur dan mengawasi keamanan pangan yang beredar di masyarakat4. Salah satu masalah keamanan pangan di Indonesia adalah masih rendahnya pengetahuan, keterampilan, dan tanggung jawab produsen pangan tentang mutu dan keamanan pangan, terutama pada industri kecil atau industri rumah tangga5. Masalah keamanan pangan tersebut juga terjadi pada makanan tradisional (Sugiyatmi,2006) 
Makanan-makanan yang selama ini diduga sebagai penyebab terjadinya kasuskasus penyakit bawaan makanan dan keracunan makanan berasal baik dari makanan keluarga maupun makanan-makanan yang diperjualbelikan di tempat-tempat pengelolaan makanan (TPM), di antaranya adalah makanan jajanan tradisional. Makanan jajanan tradisional pada umumnya dijual oleh pedagang kaki lima di tempat-tempat keramaian, terutama di pasar-pasar. Makanan ini umumnya dijual dengan harga murah dan dikonsumsi secara luas oleh berbagai lapisan masyarakat. Makanan jajanan tradisional yang dijual di pasar-pasar untuk tujuan-tujuan tertentu banyak yang ditambah dengan bahan-bahan lain, misalnya bahan pemanis, bahan penyedap, bahan pengawet, dan bahan pewarna. Di antara bahan-bahan yang ditambahkan itu sering ada yang membahayakan kesehatan manusia, misalnya boraks dan bahan-bahan pewarna yang dilarang (Sugiyatmi,2006).

Siswa-siswi SMA 2 Batang Anai Kecamatan Batang Anai Kabupaten Padang Pariaman merupakan siswa-siswi SMA perbatasan antara Padang Pariaman dengan Kota Padang. Akses menuju sekolah dari Kota Padang lebih dekat dibandingkan dari Kabupaten Padang Pariaman, Di sekitar sekolah terdapat 2 warung kantin makanan dan minuman yang dikelola oleh sekolah. Dalam sekolah ada lapangan pada musim kering bisa berdebu ketika hari panas. menyebabkan riskan terkontaminasi melalui udara terhadap makanan dan jajanan di warung-warung terdekat dan meningkatkan risiko food-borne infection yang diperantarai oleh lalat. Sekolah ini juga sering disinggahi oleh penjaja makanan kaki lima, seperti gorengan, cilok, dan bakso (dengan sepeda motor), sehingga tidak semuanya jajanan anak-anak di SMA 2 Batang Anai terjamin keamanan dan kebersihannya. Makanan yang tidak dapat dijamin keamanan dan higienitasnya ini dapat menyebabkan food poisoning bagi konsumennya.

Berdasarkan potensi adanya kontaminasi oleh faktor lingkungan terhadap jajanan dan makanan sekolah dan efek toksik (via bioakumulasi) akut, subakut, maupun kronik dari konsumsi makanan yang tidak sehat, maka kami dari perguruan tinggi berinisiatif untuk melakukan diseminasi informasi yang tepat tentang jajanan dan makanan sehat pada anak-anak sekolah menengah atas (SMA). Diseminasi informasi dalam bentuk penyuluhan ini diharapkan dapat mendukung pencegahan agar generasi penerus ini terhindar dari dampak negatif dari makanan dan jananan yang tidak sehat. Siswa SMA 2 batang anai kami pilih sebagai khalayak sasaran strategis penyuluhan karena sudah dibekali mata pelajaran IPA yang dinilai cukup mendasari pengetahuan tentang dasar-dasar higiene dan gizi makanan yang akan diberikan oleh tim. Tujuan kegiatan diseminasi ini adalah memberikan informasi masalah jajanan dan makanan sehat kepada anak-anak sekolah, pengelola kantin di sekolah SMA 2 Batang Anai.

\section{Metode Pelaksanaan}

Penyuluhan kepada masyarakat yang terdiri dari siswa-siswa SMA, pengelola kantin dan pemasok makanan jajanan dilakukan pada bulan tanggal 7 Desember tahun 2019 di Aula SMA 2 Batang Anai Kecamatan Batang Anai Kabupaten Padang Pariaman. Upaya yang dilakukan adalah dengan memberikan sejumlah materi yang relevan sesuai dengan masalah yang dijumpai dilapangan. Materi yang diberikan seperti keamanan makanan jajanan dan standar kantin sehat. Materi ini sesuai dengan target serta luaran yang diinginkan. Metode pendekatan yang dilakukan dalam kegiatan ini adalah dengan dengan metode : 
1. Metode Ceramah: Metode ini digunakan untuk memberikan pemahaman yang lengkap kepada para peserta tentang suatu topik. Dalam ceramah diuraikan kerangka materi secara lengkap, jelas, mudah dipahami, dan aplikatif. Metode ceramah dalam penyuluhan ini di gampilkan melalu power point dan diusahakan untuk menghindari pembahasan teoritis yang berlarut-larut dan lebih menekankan pada contoh-contoh kasus beserta pemecahannya.

2. Metode tanya jawab atau diskusi yang dilakukan untuk membahas terkait berbagai hambatan dan atau masalah yang dihadapi dalam kehidupan sehari-hari sehingga dapat menjalani hidup dalam keadaan sehat melalui aktifitas fisik. Diskusi dipilih untuk lebih memberikan kesempatan kepada para peserta membahas, mempertanyakan, menggaris bawahi, memberikan masukan, dan memperdalam materi yang disampaikan.

Adapun isi materi yang disampaikan kepada peserta penyuluhan sebagai berikut :

a. Kantin sehat. Pada materi disini disampaikan mulai pengertian kantin sehat, Standard Pengolahan, Penyimpanan, Penyajian, dan Pengangkutan Makanan , Standard Higienitas dan Sanitasi di Lingkungan Kantin, Standard Keselamatan Kerja di Lingkungan Kantin dan Standard Pengelolaan Kantin Sehat oleh sekolah (Lilis dkk, 2011; Anonim, 2017).

b. Keamanan Makanan Jajanan. Materi yang disampaikan mulai permasalahan makanan jajanan, syarat makanan jajanan, bahan kimia yang biasa ditambahkan pada makanan jajanan (contoh), syarat penambahan bahan tambahan pangan serta tips contoh memilih makanan jajanan yang sehat (Dewanti,2015).

\section{Hasil dan Pembahasan}

Dari hasil diskusi awal tim pelaksana dari penyiapan materi penyuluhan dengan memberikan penjelasan yang di sertakan dengan gambar bagaimana cara mewujudkan standar kantin sehat dan keamanan makanan jajanan. Adapun dokumentasi pemateri seperti gambar 1 dibawah ini.

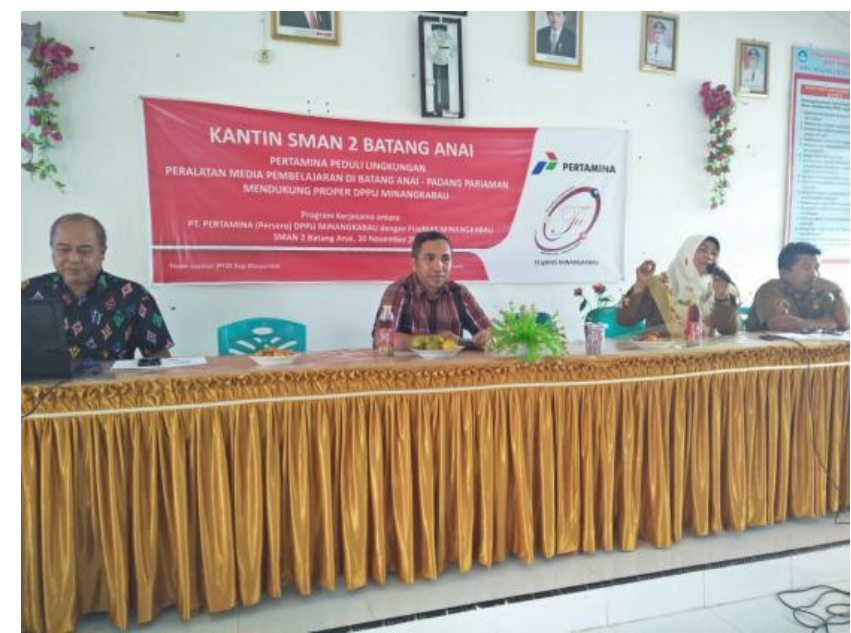

Gambar 1. Kepala sekolah SMA 2 Batang Anai sedang memberi sambutan 
Sehingga setelah peserta mendengarkan materi penyuluhan dan diskusi (Tanya jawab) dari gambar dan video yang diberikan maka peserta dapat mewujudkan kantin sehat dan melakukan pemilihan sendiri makanan jajanan yang sehat. Selama proses penyuluhan, tim pelaksana pengabdian selalu melakukan pemantauan kepada peserta dan respon yang diberikan secara umum oleh masyakat dalam hal ini peserta penyuluhan untuk mengingatkan bahwa penyuluhan ini sangat bermanfaat, karena akan berkaitan dengan kesehatan peserta kedepan. Adapun peserta penyuluhan seperti gambar 2 dibawah ini.

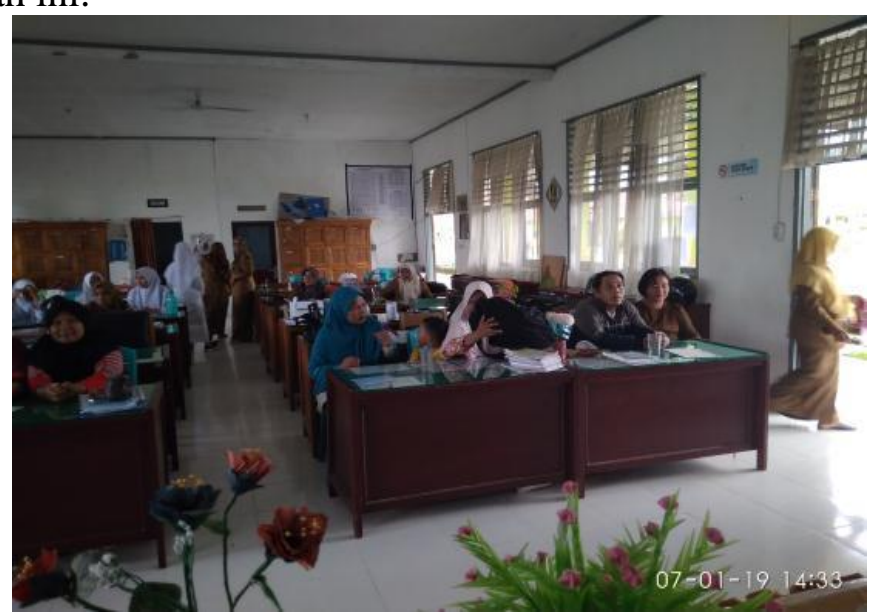

Gambar 2. Peserta penyuluhan jajanan, makanan dan kantin sehat di SMA 2 Batang Anai Kecamatan Batang Anai Kabupaten Padang Pariaman

Peserta pengabdian kepada masyarakat tentang kantin sehat dan keamanan makanan jajanan ini berjumlah 30 orang terdiri dari siswa-siswa SMA dari pengurus osis, pengelola kantin sekolah dan mitra masyarakat sekitar yang berjualan disekolah. Berdasarkan pelaksanaan penyuluhan yang berjudul penyuluhan jajanan, makanan dan kantin sehat di Aula Sekolah SMA 2 Batang Anai Kecamatan Batang Anai Kabupaten Padang Pariaman. Maka hasil yang dicapai dideskripsikan yaitu sebagai berikut:

a.Menambah wawasan pengetahuan teori maupun praktek tentang penyuluhan jajajan, makanan dan kantin sehat, sehingga dapat bermanfaat untuk kesehatan masyarakat.

b.Meningkatnya kesehatan siswa sekolah dan terwujudkan kantin sehat yang dapat memberikan efek menumbuhkan generasi sekolah yang cerdas.

c.Berdasarkan gambar dan video yang diberikan kepada peserta penyuluhan, maka setelah penyuluhan dan penjelasan secara teori peserta masyarakat langsung mempraktekkan cara pemilihan makanan dan jajanan yang sehat dan benar.

d.Pada tahapan selanjutnya para peserta penyuluhan bisa memberikan pengetahuan dan keterampilan kepada teman-temannya tentang bagaimana cara membuat, memilih jajanan, makanan yang sehat serta bisa membuat kantin sehat sehingga kebutuhan hidup sehari-hari bisa terbebas dari bahan tambahan pangan berbahaya.

Penyuluhan masalah jajanan, makanan dan kantin sehat mempunyai beberapa target, diantaranya adalah:

a.Terjadinya peningkatan pengetahuan tentang tips-tips membuat, memilih jajanan dan makan sehat termasuk bisa mewujudkan kantin sehat di Sekolah SMA 2 Batang Anai Kecamatan Batang Anai Kabupaten Padang Pariaman. 
b.Terjadinya peningkatan kualitas kesehatan siswa-siswi SMA 2 Batang Anai, dan dari pihak pengelola kantin dan masyarakat sekitar bisa mewujudkan jajajan, makanan dan kantin sehat dilingkungan masing-masing.

\section{Simpulan dan saran}

Penyuluhan masalah jajanan, makanan dan kantin sehat yang disampaikan kepada siswa siswi SMA 2 Batang Anai, pengelola kantin dan masyarakat disekitar kantin dapat terlaksana dengan baik. Hal tersebut ditandai dengan adanya kesungguhan dan antusiasme dari peserta untuk bertanya dan diskusi masalah penentuan jajajanan dan makan sehat.

Adapun saran yang disampaikan pada penyuluhan ini adalah perlu adanya pendampingan agar para peserta penyuluhan bisa mulai hidup sehat dengan makan makanan jajanan yang sehat. Untuk meningkatkan keantusiasan dalam mengikuti penyuluhan tentang jajanan dan makan sehat perlu ditambah contoh studi kasus yang lebih banyak sehingga dapat dijadikan pedoman dalam pembuatan dan memilih makanan yang sehat.

\section{UCAPAN TERIMAKASIH}

Pada kesempatan yang baik ini kami menyampaikan terimakasih yang setinggitingginya kepada : Kepala DPPU Pertamina Bandara Minangkabau Provinsi Sumatera Barat, Ketua Flipmas Minangkabau, Ketua LPPM Universitas Ekasakti beserta jajarannya dan tim, Kepala Sekolah SMA 2 Batang Anai dan Masyarakat sekitar sekolah, dan semua pihak yang telah membantu kami dalam melaksanakan kegiatan penyuluhan kepada masyarakat ini.

\section{Daftar Pustaka}

Anonim, 2013. Pedoman Pangan Jajanan Anak Sekolah Untuk Pencapaian Gizi Seimbang.Direktorat Standarisasi Produk Pangan Deputi Bidang Pengawasan Keamanan Pangan dan Bahan Berbahaya Badan Pengawas Obat dan Makanan RI.

BBPOM RI. 2009. Sistem Keamanan Pangan Terpadu Pangan Jajanan Anak Sekolah.

Dewanti T., 2015. Keamanan Makanan Jajanan. Power point kuliah. Jurusan Teknologi Hasil Pertanian Fakultas Teknologi Pertanian Universitas Brawijaya.

Lilis Nurhaida dkk, 2011. Menuju Kantin Sehat di Sekolah Edisi Tahun 2011. Direktorat Jenderal Pendidikan Dasar Kementerian Pendidikan Nasional.

Anonim, 2017 Standar layanan kantin sehat.. Fakultas Psikologi Universitas Indonesia Food Watch. 1(9). 1-4. (Akses: http://www2. pom.go.id /surv /events /pjas2009 fw.pdf)

Satriyasa.B.K., Mahendra A.N., Jawi M., Ernawati K., Sucindra D., Aman I.GM., 2017. Penyuluhan Jajanan dan Makanan Sehat pada Siswa SDN Cepaka Kelas IV-VI, Kecamatan Kediri Kabupaten Tabanan. Laporan Kegiatan Pengabdian 
kepada Masyarakat Program Studi Program Dokter Fakultas Kedokteran Universitas Udayana. Tidak dipublikasikan.

Sugiyatmi Sri, 2006. Analisis Faktor Resiko Pencemaran Bahan Toksik Boraks dan Pewarna Pada Makanan Tradisional yang dijual di Pasar-Pasar Kota Semarang tahun 2006. 